\title{
Influence of mesoporous silica coating treatment on push-out bond strength of zirconia posts
}

\author{
Xiaoli Feng ${ }^{\mathrm{a}}$, Ting Sun ${ }^{\mathrm{b}}$, Ruoyu Liu ${ }^{\mathrm{a}}$, Yanli Zhang ${ }^{\mathrm{a}}$, Aijie Chen ${ }^{\mathrm{a}}$ and Longquan Shao ${ }^{\mathrm{a}, *}$ \\ ${ }^{a}$ Department of Stomatology, Nanfang Hospital, Southern Medical University, Guangzhou 510515, \\ China \\ ${ }^{b}$ The Medical Centre of Stomatology, The 1st Affiliated Hospital of Jinan University, Guangzhou \\ 510630, China
}

\begin{abstract}
This study aimed to evaluate the influence of mesoporous silica coating surface treatments on push-out bond strength of zirconia posts. Zirconia posts (Cosmopost) were treated with vehicle (control), sandblasting plus silane application $(\mathrm{SB}+\mathrm{SI})$, a combination of sandblasting, mesoporous silica coating and silane application $(\mathrm{SB}+\mathrm{MSC}+\mathrm{SI})$ ( $n=10$ /group). Specimens were cemented with RelyX Unicem (3M ESPE, Germany) then horizontally segmented into three sections and subjected to a push-out test. Surface treatments showed significant higher bond strength than the control group, and $\mathrm{SB}+\mathrm{MSC}+\mathrm{SI}$ group presented higher values than $\mathrm{SB}+\mathrm{SI}$ group $(P<0.05)$. No significant differences were found in bond strength among root regions $(P>0.05)$. We conclude that the combination of mesoporous silica coating and silane application greatly enhance the push-out bond strength of zirconia posts.
\end{abstract}

Key words: Zirconia, posts, mesoporous silica coating, push-out, root region

\section{Introduction}

Increasing numbers of aesthetic restorations have demanded the development of post materials with better fracture resistance [1,2]. Zirconia post system was introduced in the mid-1990s, and it showed higher fracture resistance than the older posts made of cast gold or titanium [3]. Several short-term clinical studies have reported that zirconia posts yield favorable clinical results although there is a lack of long-term evidence [4]. However, several in-vitro studies had suggested that zirconia posts possessed lower retention than other types of posts $[5,6]$.

Therefore, more studies are required to develop coating materials to improve the retention of zirconia posts to dentin. Different surface treatments, such as sandblasting with aluminum oxide particles [7], etching with hydrofluoric acid [8], silane application [9], silica coating [10] or the combination of these treatments [11] to the post surface have been widely used to enhance the adhesion of feldspathic ceramics by increasing the mechanical interlocking or the chemical bond.

\footnotetext{
${ }^{*}$ Corresponding author: Longquan Shao, Department of Stomatology, Nanfang Hospital, Southern Medical University, Guangzhou 510515, China. Tel.: +15989283921; Fax: +02062787153; E-mail: shaolongquan@smu.edu.cn.
}

0959-2989/14/\$27.50 @ 2014 - IOS Press and the authors. 
However, the composition and physical properties of high-strength zirconium ceramics have large differences with silica-based ceramics. The absence of glassy phase and silicon dioxide makes them resistant to etching in hydrofluoric acid and not amenable to silanization [12]. Besides, the risk of microcrack generation with the use of air abrasion was also reported [13]. Excessive air abrasion may even induce chipping or loss of ceramics, compromising the mechanical properties and clinical performance of the ceramic restorations. Even though silica coating could enhance the bond strength between zirconium ceramics and composite resin [10], the improvement of bond strength was not satisfying. For these reasons, alternative surface treatments of zirconia prior to bonding are necessary.

There has been a growing interest on nanostructured mesoporous silica materials, which are chemically composed of silica with nanometric pores. These bioceramics exhibit intricate nanoscale porosity, which translates into surface areas above $1000 \mathrm{~m}^{2} / \mathrm{g}$, high selectivity of encapsulating biorelevant molecules and controlled surface chemistry [14]. These unique features make them particularly amenable to physical absorption and chemical modification, whereby organic molecules may be combined to produce new functional materials with great stability [15]. It is reported that mesoporous silica materials has been used in dental composites considering their potentiality in creating micromechanical filler/resin matrix bonding at the interface [16]. However, the roles of mesoporous silica coating on resin luting agents and zirconium ceramics in their bonding strength have not been examined yet.

Based on the above rationale, we aimed to evaluate the influence of mesoporous silica coating treatment and silane application on push-out bond strength of zirconia posts in root canals. We hypothesized that mesoporous silica coating treatment followed by silane application could greatly improve the bonding strength between zircornia posts and the resin composites.

\section{Experimental methods and materials}

\subsection{Specimen preparation}

This study was performed with the approval of the local ethical committee. Thirty permanent singlerooted teeth were collected and none of these teeth had carries, cracks or restorations. $2 \mathrm{~mm}$ above the mid facial cemento-enamel junction (CEJ) perpendicular to the bonded interface were sectioned using a diamond disc (Songfeng Corporation, China) in order to form a flat surface. Hand files (SybronEndo, CA) were used to instrument root canals, which were then irrigated with $20 \mathrm{ml} 5.25 \%$ sodium hypochlorite $(\mathrm{NaOCl})$ (Nanguo Corporation, China) and dried using paper points (Edward Corporation, China). Lateral condensation technique with gutta percha (Edward Corporation, China) was carried out for root canal obturation. Afterwards, post spaces were prepared to form a space with $9 \mathrm{~mm}$ in length and $1.8 \mathrm{~mm}$ in diameter.

\subsection{Fabrication of suspension of mesoporous silica particles}

In a typical procedure, tetraethyl orthosilicate (TEOS) $(3.2 \mathrm{~g})$, ethanol $(2.3 \mathrm{~g})$, Pluronic F-127 (1.0 g) and $\mathrm{HNO}_{3}(0.54 \mathrm{~g}, 0.3 \mathrm{~mol} / \mathrm{l})$ were mixed at room temperature for half an hour to produce suspension of mesoporous silica particles. 


\subsection{Surface treatment}

Zirconia posts (20 $\mathrm{mm}$ in length and $1.7 \mathrm{~mm}$ in diameter; Ivoclar, Liechtenstein) were divided into three groups $(\mathrm{n}=10)$ according to the following surface treatments: Control group: no treatment; sandblasting and silane application group $(\mathrm{SB}+\mathrm{SI})$ : blasting with $50-\mu \mathrm{m} \mathrm{Al}_{2} \mathrm{O}_{3}$ particles at $0.28 \mathrm{MPa}$ for $15 \mathrm{~s}$ at a distance of $10 \mathrm{~mm}$ followed by silane application (ESPE Sil, USA); sandblasting then mesoporous silica coating and silane application group ( $\mathrm{SB}+\mathrm{MSC}+\mathrm{SI})$ : firstly blasting with $50-\mu \mathrm{m}$ $\mathrm{Al}_{2} \mathrm{O}_{3}$ particles at $0.28 \mathrm{MPa}$ for $20 \mathrm{~s}$ at a distance of $10 \mathrm{~mm}$, then mesoporous silica coating with a coating machine (SYDC-I, Sanyan Corporation) and drying for $1 \mathrm{~h}$ in the oven upon gelation at room temperature, later heat treating at $400^{\circ} \mathrm{C}$ for $2 \mathrm{~h}$ to remove the Pluronic F-127 template followed by silane application (ESPE Sil, USA).

\subsection{Post cementation}

Posts were cemented with RelyX Unicem, a self-adhesive and dual-polymerized resin cement (3M ESPE, Germany). Root canals were first washed with water and dried. The bonding material was then directly applied into the root canal. The post was placed into the depth of the root canal by finger pressure, which lasted for 8 min after cementation. An explorer was used to remove excess cement. Finally, the bonding material was polymerized using an ultraviolet curing light from different axial angles for $40 \mathrm{~s}$. The specimens were thereafter stored in distilled water at $37^{\circ} \mathrm{C}$ for $24 \mathrm{hrs}$.

\subsection{Sectioning of tooth segments}

Tooth segments were firstly mounted in acrylic resin and then horizontally sectioned under water cooling to produce 4 sections. The top $0.5-\mathrm{mm}$ section was discarded considering the containing of the extra portion of the post and excess bonding material. Afterwards, the remaining tooth sections (coronal, middle and apical) each with a $1.5 \mathrm{~mm}$ in height were prepared and used for the push-out test.

\subsection{Push-out test}

A universal testing machine (Lloyd Instruments, UK) was used to perform the push-out test. Load application was performed with a special constructed tip $(1.2 \mathrm{~mm}$ in diameter), which was centered on the post section only. The tip pushed the post at a crosshead speed of $0.5 \mathrm{~mm} / \mathrm{min}$. The maximal dislodging force that made extrusion of the specimen was recorded. Bonding strength values were calculated using the following equation:

$$
\mathrm{PBS}=\mathrm{F} / \mathrm{A}
$$

Where PBS is bond strength values (MPa), $\mathrm{F}$ is the peak force $(\mathrm{N}), \mathrm{A}$ is the adhensive area $\left(\mathrm{mm}^{2}\right)$. The bonded area was the lateral surface of the cylinder, which was calculated according to the equation:

$$
\mathrm{A}=2 \pi \mathrm{rh}
$$


Where $\pi$ is constant $=3.14, \mathrm{r}$ is the radius of the post, and $\mathrm{h}$ is the thickness of each section.

\subsection{Observation of post/cement bonded interface}

To observe the micro morphology of cement/post bonded interface, additional 2 coronal, 2 middle and 2 apical sections were selected in each group before the push-out test and coated with goldpalladium alloy using a sputter-coating technique (Anatech Ltd, Alexandria). A scanning electron microscopy (SEM) (FEI, Holland) was utilized to examine the sections at $\times 3000$ magnification at 20 $\mathrm{Kv}$.

\subsection{Statistical analysis}

Two-way ANOVA was conducted to analyse the data of push-out bond strength values. Tukey's HSD test $(\alpha=0.05)$ was performed to test statistical differences between groups. All analyses were conducted using the SPSS 13.0 software.

\section{Results}

\subsection{Bonding strength of zirconia post to dentin}

Descriptive data are presented in Table 1. The two-way ANOVA analysis is presented in Table 2, which indicated significant differences in mean bond strength values among different surface

Table 1

Mean values of push-out bond strength (MPa) of zirconia posts using different surface treatments

\begin{tabular}{lcll}
\hline Surface treatment & Bond strength $(\mathrm{MPa})$ & Root region & Bond strength $(\mathrm{MPa})$ \\
\hline Control & $7.15 \pm 0.87$ & Coronal & $7.22 \pm 0.95$ \\
& & Middle & $6.99 \pm 0.81$ \\
& & Apical & $6.82 \pm 0.76$ \\
$\mathrm{SB}+\mathrm{SI}$ & Coronal & $9.13 \pm 1.20$ \\
& \multirow{2}{*}{$0.84 \pm 0.92$} & Middle & $8.83 \pm 1.13$ \\
& & Apical & $8.40 \pm 1.06$ \\
$\mathrm{SB}+\mathrm{MBC}+\mathrm{SI}$ & \multirow{2}{*}{$15.73 \pm 1.68$} & Coronal & $16.11 \pm 1.84$ \\
& & Middle & $15.82 \pm 1.53$ \\
& & Apical & $15.13 \pm 1.17$ \\
\hline
\end{tabular}

Table 2

Two-way ANOVA on effects of surface treatments and root regions

\begin{tabular}{llllll}
\hline \multicolumn{1}{c}{ Source } & $\begin{array}{l}\text { Type III Sum of } \\
\text { Squares }\end{array}$ & df & Mean Square & F & Sig. \\
\hline Surface treatment & 1323.831 & 2 & 661.915 & 987.136 & .000 \\
Root region & 3.660 & 2 & 1.830 & 2.729 & .071 \\
Surface treatment* & .519 & 4 & .130 & .193 & .941 \\
$\quad$ root region & 54.314 & 81 & .671 & & \\
Error & 11424.251 & 90 & & & \\
Total & & & & & \\
\hline
\end{tabular}


treatments $(P<0.05)$ while no statistical differences among root regions $(P>0.05)$. The mean push-out bond strength in $\mathrm{SB}+\mathrm{MSC}+\mathrm{SC}$ group was the highest $(15.23 \pm 1.68 \mathrm{MPa})$, while the values in the control group was the lowest $(7.15 \pm 0.87 \mathrm{MPa})$. Multiple comparisons with Tukey's HSD test revealed the bond strength between any two groups had a significant difference $(P<0.05) . \mathrm{n}=10$ /group.

\subsection{Illustration}

The cementation process of zorconia post to root canal is shown in Figure 1.

\subsection{Microscopy}

Representative SEM photographs of control group (a), SB+SI group (b), SB+MBC+SI group (c) are shown in Figure 2 at a magnification of $\times 3000$, demonstrating micromorphology of the post/cement bonded interface.

\section{Discussion}

Tensile and shear tests are most commonly used to assess post retention. However, the two tests are not capable to exert uniform stresses on the tooth surface-due to the large bonding surface area [17]. Microtensile test has overcome these shortcomings with a smaller bonding area. But high premature

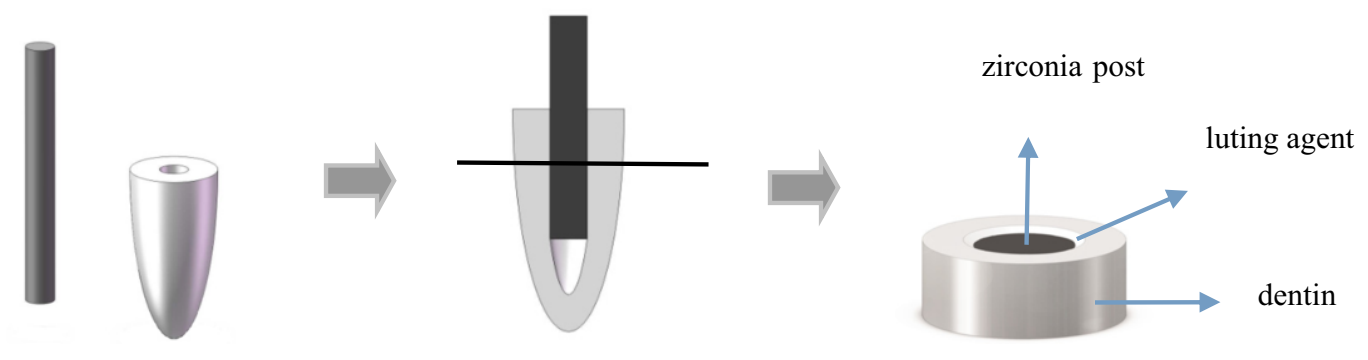

Fig. 1. The schematic illustration of the post cementation.

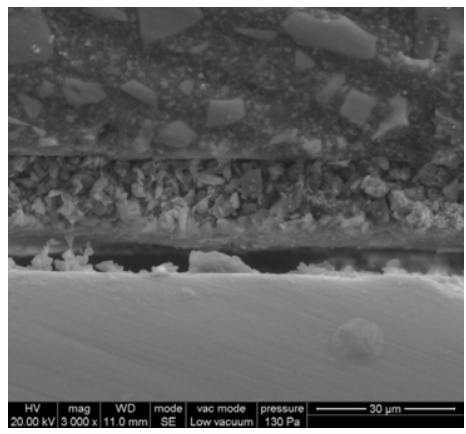

(a)

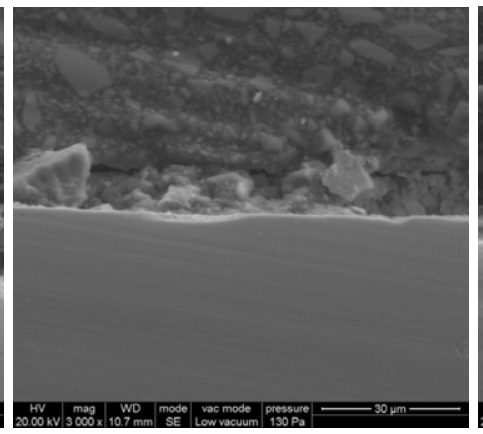

(b)

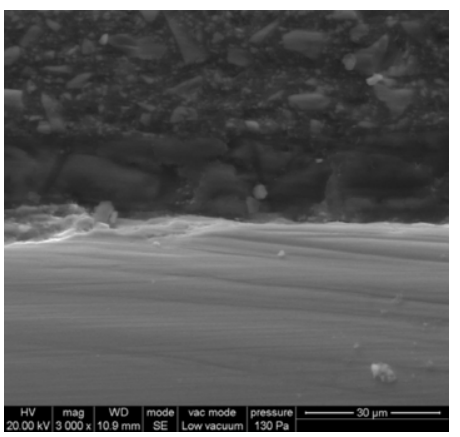

(c)

Fig. 2. Representative SEM photographs (original magnification $\times 3000$ ) of post/cement bonded interface: (a) control group, (b) $\mathrm{SB}+\mathrm{SI}$ group, (c) $\mathrm{SB}+\mathrm{MBC}+\mathrm{SI}$ group. 
failure rate during specimen preparation and large data distribution still exist in the microtensile test methodology [18]. Instead, a compromise between the above tests can be offered by push-out tests by using post segments of 1-2 $\mathrm{mm}$ in height, which features smaller bonding areas but avoids premature failures. Therefore, a push-out test was adopted in the study.

In the control and SB+SI group, the resin composite did not infiltrate into surface of zirconia post. However, complete fusion of post/cement bonded interface was observed in SB+MSC+SI group (Figure 2). Although it is not recommended to alter post surfaces by the manufacturer of Cosmopost [19], the present study has shown that the application of surface treatments greatly improve bond strength with resin luting agent. The low bond strength values between untreated zirconia posts and composite resin may be attributed to the smooth surface of the posts, which prevent any macromechanical and micro mechanical retention to resin luting agents [20]. Therefore, evaluation of the effect of surface treatments on bond strength of zirconia posts is necessary.

The present study evaluated several surface treatments including mechanical and chemical bonding procedures. In $\mathrm{SB}+\mathrm{SI}$ group, mechanical bonding was achieved by roughening post surfaces using 50 $\mu \mathrm{m}$ grain sized $\mathrm{Al}_{2} \mathrm{O}_{3}$ particles. The roughening procedure increases the total bonding area and the wettability of the zirconia post with resin luting agent [21]. Madani et al. [22] and Awliya et al. [23] found that airborne-particle abrasion was more effective in producing high bond strength between resin luting agent and a zirconium ceramic substrate compared to hydrofluoric acid, a diamond rotary cutting instrument grinding, or polishing treatments. In addition, the application of silane coupling agent also contributes to the bonding values by promoting a chemical bond to resinous materials via cross-linkages with methacrylate groups as well as improving the substrate surface energy and surface wettability to resin [24].

Nevertheless, the bond strength value in $\mathrm{SB}+\mathrm{SI}$ group $(8.84 \pm 0.92 \mathrm{MPa})$ was significant lower compared to that in $\mathrm{SB}+\mathrm{MSC}+\mathrm{SI}$ group, which supports the hypothesis that the bond strength between zirconia posts and the resin composites could be greatly improved by using mesoporous silica coating treatment. This finding may be explained with the combination of nanostructured mesoporous silica materials, whose chemical composition is silica present in nanometric pores, and silane coupling agent. Although surface roughening creates mechanical retentive areas where silane molecules lodge and link inorganic molecules of the ceramic crystalline phase to organic molecules in the resinous material, improvement of the bond strength between high-strength ceramics and resin may be limited because of low silica content of these materials [25]. Therefore, the silica-coating technique in SB+MSC+SI group is supposed to increase the surface silica content and to establish chemical silica-silane (siloxane) bonding. Furthermore, nanostructured mesoporous silica materials, including mesoscopic order, tunable pore dimensions in the molecular size range, a high pore volume and surface area [26], allows for much higher bonding area and surface energy, as well as a great improvement of surface wettability to resin. Difference in surface texture among SEM photographs further confirms that silane infiltrating roughened structures is facilitated by mesoporous silicone coating.

The mesoporous silica material used in this study was prepared by using a surfactant template solution-gelatin (sol-gel) method. This method involves inserting a surfactant template to $\mathrm{HNO}_{3}$ catalyzed sol-gel reaction of tetraethyl orthosilicate. The templates are removed by heating when the monolith is generated, leaving the silica particles like interconnected porous structure [27]. This system has an advantage that silica-coating units are available without the requirements of special equipments or high expenses. It has been reported that a tribochemical silica coating could increase the bond strength between high-strength ceramics and resin luting agent [10,11]. However, this silicacoating method is technically complicated and cannot produce nanometric coating matercials. 
A number of studies have been conducted to investigate the effect of bonding materials on the renention of zirconia posts to denin. It is known that conventional bonding materials such as glass ionomer and resin-modified glass ionomer provide lower retention compared to adhesive resin luting agents [28-30]. In addition, conventional resin cements are reported to be less capable than chemically adhesive resin cements [31]. RelyX Unicem is a representative self-adhesive resin cement, which posesses high chemical bonding capacity to dentin because of its contents-phosphoric acid monomer and methacrylate monomers [32]. Bitter et al. [33] indicated that the bond strength of zirconia posts cemented with RelyX Unicem resin cement was similar to other types of chemically adhesive resin cements. Considering this reason, RelyX Unicem was selected as the bonding material in the present study.

Considering the influence of different root regions on bond strength values in this investigation, the coronal sections were found to have the highest values and apical sections demonstrated the lowest values regardless of the surface treatment used (Table 1). However, there were no significant differences among different root regions. This finding can be explained with the simplified cementation process of RelyX Unicem which does not require pretreatment and is applied directly into the root canals. This result is consistent with other studies [34,35].

It was also reported that the high initial bond strength of zirconia posts obtained by surface treatments might decrease due to artificial aging such as water storage at a constant temperature [36]. However, the current study was limited to test instant bond strength. Consequently, more investigations on the evaluation of the influence of surface treatments on retentive values after artificial aging are necessary. Moreover, other mechanical properties, such as flexural strength of zirconia posts with the use of mesoporous silica coating should also be analysed.

In summary, the combination of mesoporous silica coating and silane application can significantly increase the bond strength between zirconia posts and resin luting agents. In contrast, the root regions have no significant influence on the bonding strength between zirconia posts to dentin when cemented with RelyX Unicem.

\section{Acknowledgment}

This work was supported by National Natural Science Foundation (31070857 and 50973045), Project on the Integration of Industry, Education and Research of Guangdong Province (2012B091000147) and Open Project Program of Shanghai Institute of Ceramics, Chinese Academy of Sciences (SKL201207SIC).

\section{References}

[1] A.R. Giovani, L.P. Vansan, M.D. de Sousa Neto and S.M. Paulino, In vitro fracture resistance of glass-fiber and cast metal posts with different lengths, J. Prosthet. Dent. 101 (2009), 183-188.

[2] G. Akgungor, D. Sen and M. Aydin, Influence of different surface treatments on the short-term bond strength and durability between a zirconia post and a composite resin core material, J. Prosthet. Dent. 99 (2008), 388-399.

[3] G. Heydecke, F. Butz, A. Hussein and J.R. Strub, Fracture strength after dynamic loading of endodontically treated teeth restored with different post and core systems, J. Prosthet. Dent. 87 (2002), 438-445.

[4] F.P. Nothdurft and P.R. Pospiech, Clinical evaluation of pulpless teeth restored with conventionally cemented zirconia posts: a pilot study, J. Prosthet. Dent. 95 (2006), 311-314.

[5] A. Sahafi, A. Peutzfeld, E. Asmussen and K. Gotfredsen, Effect of surface treatment of prefabricated posts on bonding of resin cement, Opera. Dent. 29 (2004), 60-68. 
[6] J. Perdigao, S. Geraldeli and I.K. Lee, Push-out bond strengths of tooth-colored posts bonded with different adhesive systems, Am. J. Dent. 17 (2004), 422-426.

[7] S. Bhargava, H. Doi, R. Kondo, H. Aoki, T. Hanawa and S. Kasugai, Effect of sandblasting on the mechanical properties of Y-TZP zirconia, Biomed. Mater. Eng. 22 (2012), 383-398.

[8] R.C. de Oyagüe, F. Monticelli, M. Toledano, E. Osorio, M. Ferrari and R. Osorio, Influence of surface treatments and resin cement selection on bonding to densely-sintered zirconium-oxide ceramic, Dent. Mater. 25 (2009), 172-179.

[9] S. Kitayama, T. Nikaido, M. Ikeda, S. Alireza, H. Miura and J. Tagami, Internal coating of zirconia restoration with silica-based ceramic improves bonding of resin cement to dental zirconia ceramic, Biomed. Mater. Eng. 20 (2010), 7787.

[10] A.A. Xible, R.R. de Jesus Tavarez, R. de Araujo Cdos and W.C. Bonachela, Effect of silica coating and silanization on flexural and composite-resin bond strengths of zirconia posts: An in vitro study, J. Prosthet. Dent. 95 (2006), 224-229.

[11] S.S. Atsu, M.A. Kilicarslan, H.C. Kucukesmen and P.S. Aka, Effect of zirconium-oxide ceramic surface treatments on the bond strength to adhesive resin, J. Prosthet. Dent. 95 (2006), 430-436.

[12] G.A. Borges, A.M. Sophr, M.F. de Goes, L.C. Sobrinho and D.C. Chan, Effect of etching and airborne particle abrasion on the microstructure of different dental ceramics, J. Prosthet. Dent. 89 (2003), 479-488.

[13] Y. Zhang, B.R. Lawn, E.D. Rekow and V.P. Thompson, Effect of sandblasting on the long-term performance of dental ceramics, J. Biomed. Mater. Res. B Appl. Biomater. 71 (2004), 381-386.

[14] A.E. Garcia-Bennett, Synthesis, toxicology and potential of ordered mesoporous materials in nanomedicine, Nanomedicine (Lond) 6 (2011), 867-877.

[15] R. Smaail, N. Basbas, S. Tighadouini, M. Bacquet, S. Degoutin and F. Cazier, New amine-modified silicas: synthesis, characterization and its use in the $\mathrm{Cu}(\mathrm{II})$-removal from aqueous solutions, Progress in Nanotechnology and Nanomaterials 2 (2013), 108-116.

[16] S.P. Samuel, S. Li, I. Mukherjee, Y. Guo, A.C. Patel, G. Baran and Y. Wei, Mechanical properties of experimental dental composites containing a combination of mesoporous and nonporous spherical silica as fillers, Dent. Mater. 25 (2009), 296-301.

[17] C. Goracci, S. Grandini, M. Bossu, E. Bertelli and M. Ferrari, Laboratory assessment of the retentive potential of adhesive posts: A review, J. Dent. 35 (2007), 827-835.

[18] C. Goracci, A.U. Tavares, A. Fabianelli, F. Monticelli, O. Raffaelli, P.C. Cardoso, F. Tay and M. Ferrari, The adhesion between fiber posts and root canal walls: comparison between microtensile and push-out bond strength measurements, Eur. J. Oral. Sci. 112 (2004), 353-361.

[19] C. Oblak, P. Jevnikar, T. Kosmac, N. Funduk and L. Marion, Fracture resistance and reliability of new zirconia posts, J. Prosthet. Dent. 91 (2004), 342-348.

[20] F. Al-harbi and D. Nathanson, In vitro assessment of retention of four esthetic dowels to resin core foundation and teeth, J. Prosthet. Dent. 90 (2003), 547-555.

[21] R. Amaral, M. Ozcan, M.A. Bottino and L.F. Valandro, Microtensile bond strength of a resin cement to glass infiltrated zirconia-reinforced ceramic: the effect of surface conditioning, Dent. Mater. 22 (2006), 283-290.

[22] M. Madani, F.C.S. Chu, A.V. McDonald and R.J. Smales, Effects of surface treatments on shear bond strengths between a resin cement and an alumina core, J. Prosthet. Dent. 83 (2000), 644-647.

[23] W. Awliya, A. Oden, P. Yaman, J.B. Dennison and M.E. Razzoog, Shear bond strength of a resin cement to densely sintered high-purity alumina with various surface conditions, Acta. Odontol. Scand. 56 (1998), 9-13.

[24] B.A. Della, K.J. Anusavice and J.A. Hood, Effect of ceramic surface treatment on tensile bond strength to a resin cement, Int. J. Prosthodont. 15 (2002), 248-253.

[25] M. Ozcan, H.N. Alkumru and D. Gemalmaz, The effect of the surface treatment on the shear bond strength of luting cement to glass-infiltrated alumina ceramic, Int. J. Prosthodont. 14 (2001), 335-339.

[26] J.M. Rosenholm, C. Sahlgren and M. Lindén, Multifunctional mesoporoussilica nanoparticles for combined therapeutic, diagnostic and targeted action in cancer treatment, Curr. Drug. Targets 12 (2011), 1166-1186.

[27] Y. Wei, J. Xu, H. Dong, J.H. Dong, K. Qiu and S.A. Jansen-Varnum, Preparation and physisorption characterization of the glucose-templated mesoporous silica sol-gel materials, Chem. Mater. 11 (1999), 2023-2029.

[28] C.R. Gernhardt, K. Bekes and H.G. Schaller, Short-term retentive values of zirconium oxide posts cemented with glass ionomer and resin cement:an in vitro study and a case report, Quintessence International 36 (2005), 593-601.

[29] S. Marchan, L. Coldero, R. Whiting and S. Barclay, In vitro evaluation of the retention of zirconia-based ceramic posts luted with glass ionomer and resin cements, Brazilian Dental Journal 16 (2005), 213-217.

[30] K. Bitter, K. Priehn, P. Martus and A.M. Kielbassa, In vitro evaluation of push-out bond strengths of various luting agents to tooth-colored posts, J. Prosthet. Dent. 95 (2006), 302-310.

[31] A. Sahafi, A. Peutzfeld, E. Asmussen and K. Gotfredsen, Effect of surface treatment of prefabricated posts on bonding of resin cement, Oper. Dent. 29 (2004), 60-68. 
[32] K.I. Aleisa, B.S. Almufleh, S.M. Morgano and C.D. Lynch, Effect of types of luting agent on push-out bond strength of zirconium oxide posts, J. Dent. 41 (2013), 377-383.

[33] K. Bitter, K. Priehn, P. Martus and A.M. Kielbassa, In vitro evaluation of push-out bond strengths of various luting agents to tooth-colored posts, J. Prosthet. Dent. 95 (2006), 302-310.

[34] G.M. Gomes, O.M. Gomes, A. Reis, J.C. Gomes, A.D. Loguercio and A.L. Calixto, Regional bond strengths to root canal dentin of fiber posts luted with three cementation systems, Braz. Dent. J. 22 (2011), 460-467.

[35] P. Oskoee, E. Navimipour, M. Oskoee, M. Bahari and F. Purnaghiazar, Effect of different adhesion strategies on pushout bond strength of fiber reinforced composite posts, African Journal of Biotechnology 10 (2011), 17593-17598.

[36] G. Akgungor, D. Sen and M. Aydin, Influence of different surface treatments on the short-term bond strength and durability between a zirconia post and a composite resin core material, J. Prosthet. Dent. 99 (2008), 388-399. 